\title{
Design of Intelligent Control System of Transformer Oil Temperature
}

\author{
Caijun Xu \\ School of Electronic and Electrical Engineering \\ Shanghai University of Engineering Science, SUES \\ Shanghai, China \\ Liping Zhang* \\ School of Electronic and Electrical Engineering \\ Shanghai University of Engineering Science, SUES \\ Shanghai, China
}

\author{
Yuchen Chen \\ School of Electronic and Electrical Engineering \\ Shanghai University of Engineering Science, SUES \\ Shanghai, China \\ Zhifeng Liu \\ School of Electronic and Electrical Engineering \\ Shanghai University of Engineering Science, SUES \\ Shanghai, China
}

\begin{abstract}
-in working process of power transformer, which directly affects the safe operation of transformer oil temperature as well as the stability of the network, so vital to transformer oil temperature detection and control. Based on single chip and chip design of digital temperature measurement transformer oil temperature of an intelligent control system. The system uses a digital temperature sensor DS18B20 collection transformer oil temperature, improves the accuracy of the system. The low power consumption, strong anti-jamming ability of the SCM STC89C51 as the main controller to achieve control and real-time monitoring of transformer oil temperature, and input control module is designed for different transformer oil temperature preset control during normal operation, improving system usability and human-computer interaction.
\end{abstract}

Keywords-transformer oil temperature; temperature control; STC89C51; DS18B20

\section{INTRODUCTION}

The core of transformer substation equipment, transformer repair and maintenance is a priority for maintenance personnel[1].Transformer oil temperature monitoring is maintaining and inspecting the top priority.Transformer transformer with high oil temperature will accelerate the ageing of the insulating materials, insulating materials combustion faults of transformer internal short-circuit caused by aging, rapid expansion after short circuit of transformer oil burning, transformers exploded, causing enormous economic loss and even cause accidents. In the usual maintenance work, we know transformer oil temperature gauge often fail, but poor accuracy, timeliness is not strong, and seriously affect the safe operation analysis of transformer[2,3].

In order to achieve real-time intelligent monitoring and control system of transformer oil temperature, presented by single-chip microcomputer controlled transformer cooling device the conventional control methods were improved, designed a new type of intelligent control system for temperature of transformer oil. This article gives detailed design of intelligent control system of transformer oil temperature, system design, enhanced human-computer interaction, the system is more stable and reliable[4]. The transformer oil temperature control system meets the requirements for stable and secure operation of transformer substation, for intelligent substation and laid a good foundation. Can be widely used in a variety of transformer oil temperature detection and control.

\section{CONTROL SYSTEM DESIGN}

As shown in Fig.1, the master controller, keyboard module, the temperature acquisition module, temperature control module, display module, alarm module, which is made up of the transformer oil temperature intelligent control system.

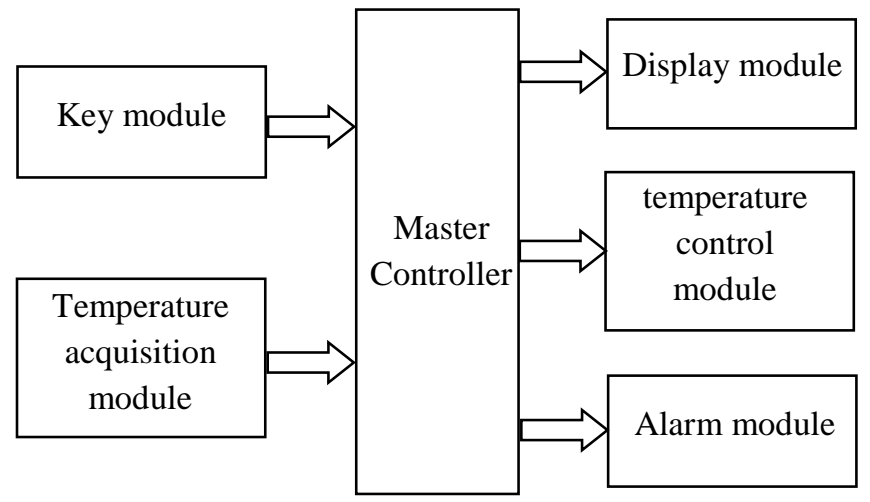

Fig. 1. block diagram of control system design

From Fig.1, we can know when the system is powered, user can through the keyboard module input preset temperature, then transmitted to the main controller processing. When the system real-time collection of temperature and the preset temperature do not match, the alarm module sends an alarm signal. At the same time, start the output control module, which makes the temperature control equipment work, adjust the system's temperature and displayed the real time temperature of the collected temperature value. When real-time acquisition of the temperature exceeds the preset temperature, control system start alarm circuit and sends out an alarm signal. At the same time to start cooling device to reduce system temperature. Repetition the transformer oil temperature is stable within the expected range. 


\section{HARDWARE DESIGN OF CONTROL SYSTEM}

Control system structure is determined, each module needs to be designed.

\section{1) The main controller module}

Main controller is the core of the whole system of intelligent control. According to the system to achieve the function, main controller with input and output port is used to control the input and output module, also the main controller have programming control, considering the needs of all aspects, can be used in high reliability, strong processing ability, high speed, control function of single chip STC89C51 as the main controller[5,6].

\section{2) The temperature acquisition module}

Considering transformer oil temperature control system to realize function of high precision temperature measurement and can be used small, low power consumption, high performance digital temperature sensor DS18B20 acquisition temperature [7,8]. In the system the module is mainly the transformer oil temperature signal acquisition, and conversion to digital signal. It's can achieve an accuracy of $\pm 0.5^{\circ} \mathrm{C}$ oil temperature detection. Maintenance personnel can display real-time data direct access to current transformer oil temperature. The circuit diagram is shown in Figure 2.

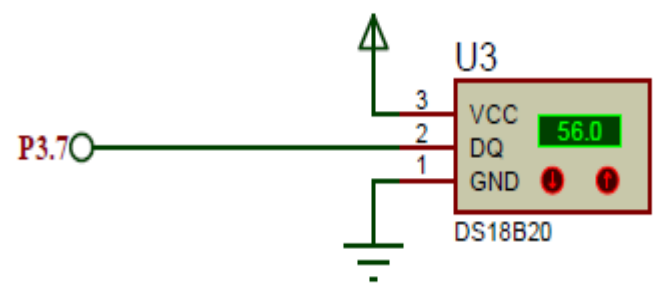

Fig. 2. The temperature acquisition module

\section{3) The temperature display module}

Considering the need to implement real-time temperature monitoring function, you can select LCD1602 with practical, cost-effective as the display module, because the LCD1602 has high display quality, digital interface, simple and comparatively small size, light weight and so on. Temperature display module in the system's main function is: displays the preset temperature value and the acquisition value, so as to achieve the purpose of real-time monitoring of transformer oil temperature. The circuit diagram is shown in Figure 3.

\section{4) The temperature control module}

In order to realize intelligent control of the temperature of transformer oil in this design system, the temperature control module mainly consists of the relay and the cooling device, which is the control of the external load of the relay[9]. By the key circuit input setting value, while the temperature acquisition circuit to obtain the current temperature signal, and then the temperature signal sent to the MCU processing. If real-time acquisition of transformer oil temperature higher than the temperature preset limit value, the micro-controller will drive the alarm module, and sends out the alarm signal, and driving cooling equipment work, when the temperature dropped to normal range and cooling equipment to stop working. To realize temperature intelligent control, to ensure that the transformer can work normally. The circuit is shown in figure 4 .

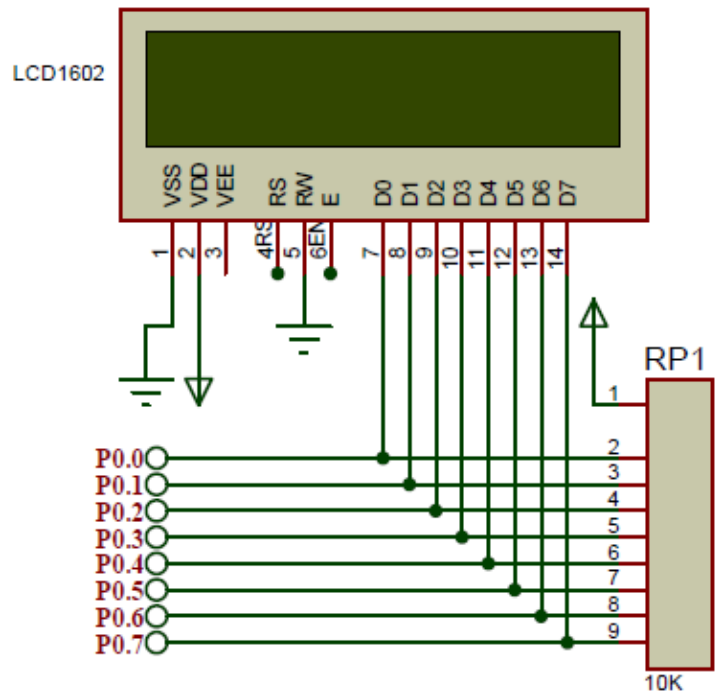

Fig. 3. The temperature display module

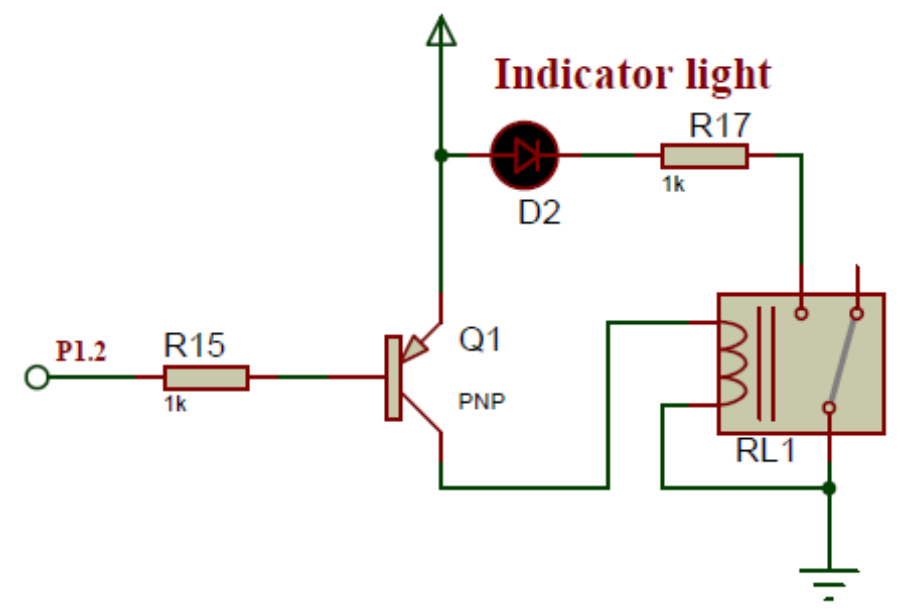

Fig. 4. The temperature control module

\section{5) The alarm module}

The core component of the alarm module is a buzzer. When the oil temperature of the real-time acquisition value exceeds the preset value, the micro-controller will drive the alarm module, light-emitting diode light, buzzer alarm signal, attract the attention of maintenance personnel. The circuit is shown in figure 5 .

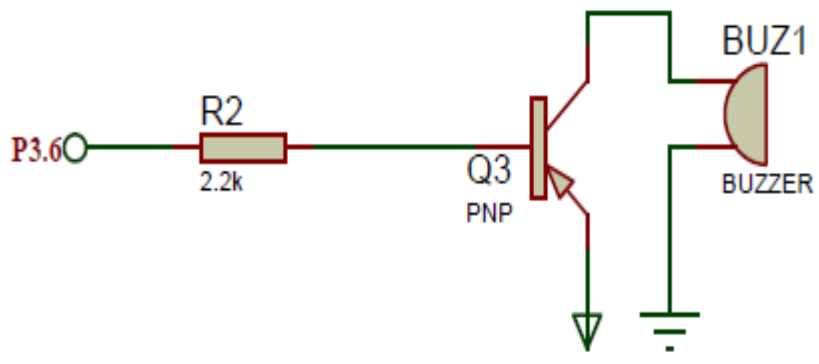

Fig. 5. The alarm module 


\section{Software Design AND SimUlation OF CONTROL} SYSTEM

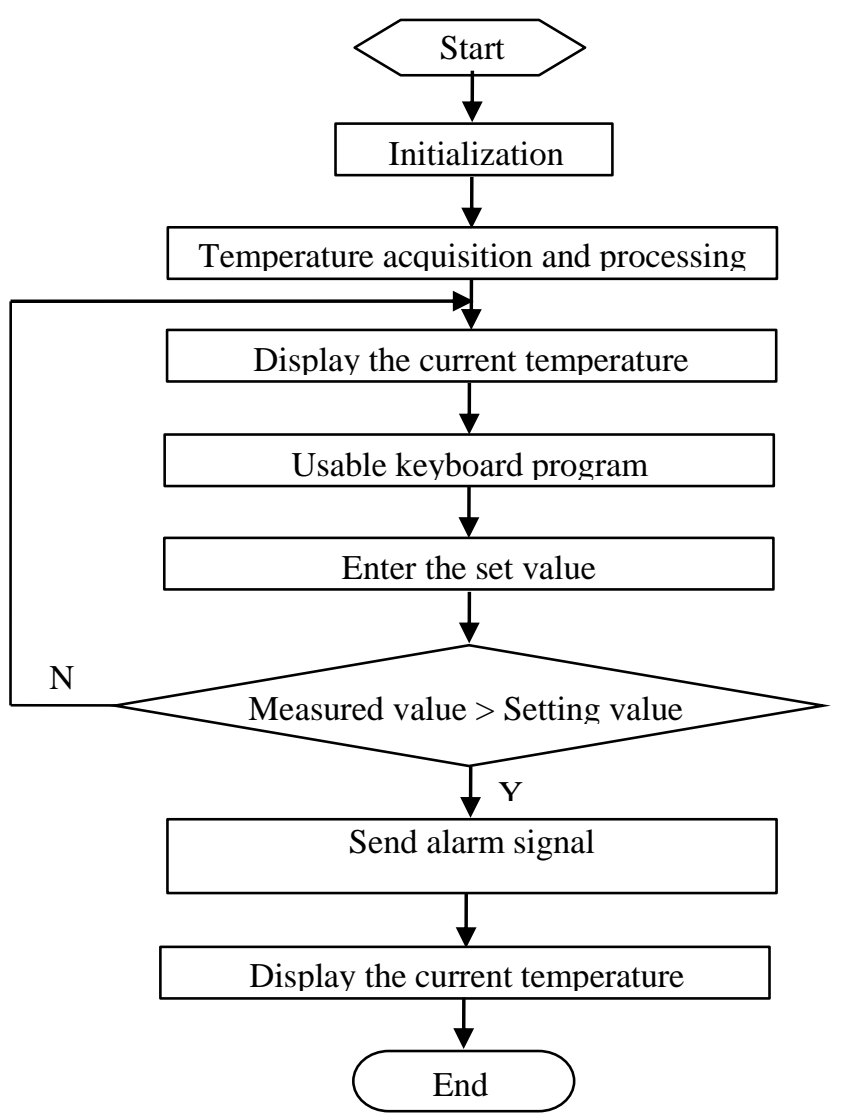

A. Main program flow diagrams of control system Software design of control system

According to the functions of the control system, the system can be divided into several modules of software design program. Then analyze the module program algorithm to finally write the procedure meets mission requirements[10]. Key handling subroutine is mainly input data to the MCU.Temperature acquisition program is the temperatures of the collecting system, and convert analog signals into digital signals.

Display subroutine is mainly display the temperature signal. By more than a few function subprogram, temperature sensors, controllers, integrated with the function of temperature control device, transformer oil temperature intelligent control, control systems of the main program flow is shown in Figure 6.

\section{B. Simulation of control system}

After the completion of the hardware and software design, it is also required by the software simulation to verify the function of the system to achieve. In this design will use the Proteus software to simulate and verify, Proteus software not only has the function of simulation, but also can simulate the MCU and peripheral devices, is the best tool for microcontroller and peripheral device simulation. Proteus is one of the most famous simulation software in the world[11]. It is the whole process from the concept to the product.

When transformer oil temperature is higher than the preset value, the MCU P1.1 output low level, buzzer alarm signal, cooling temperature indicator lights, controlled cooling equipment of relay, drive the load to cool the system, the simulation results as shown in Figure 7.

When the transformer oil temperature in the system temperature setting value range, temperature sensor continuous acquisition temperature signal, transfer to the microcontroller processing, single chip processor, the system maintained at a constant temperature and the simulation result as shown in Figure 8. 


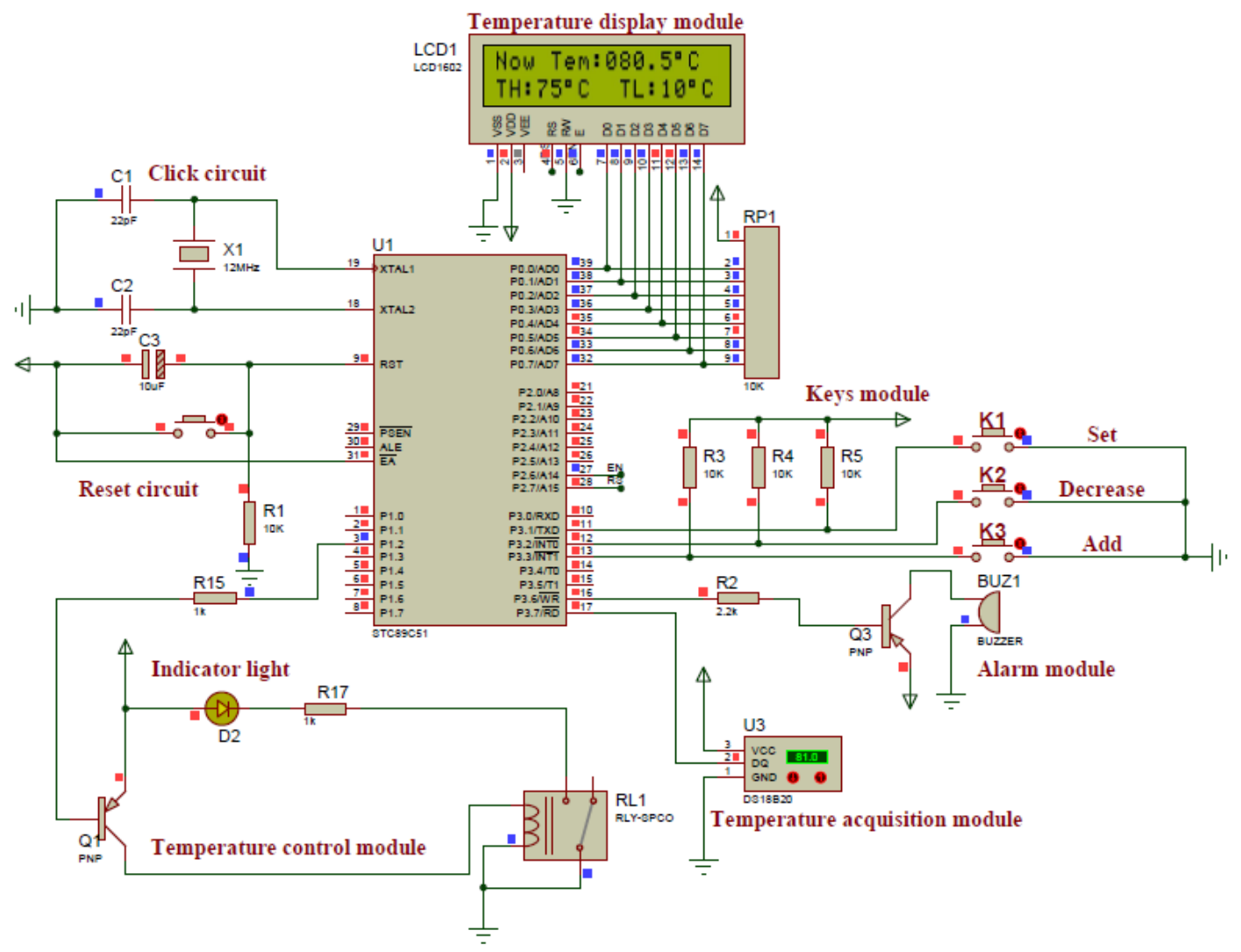

Fig. 6. Simulation of transformer oil temperature exceeds the set temperature the system value

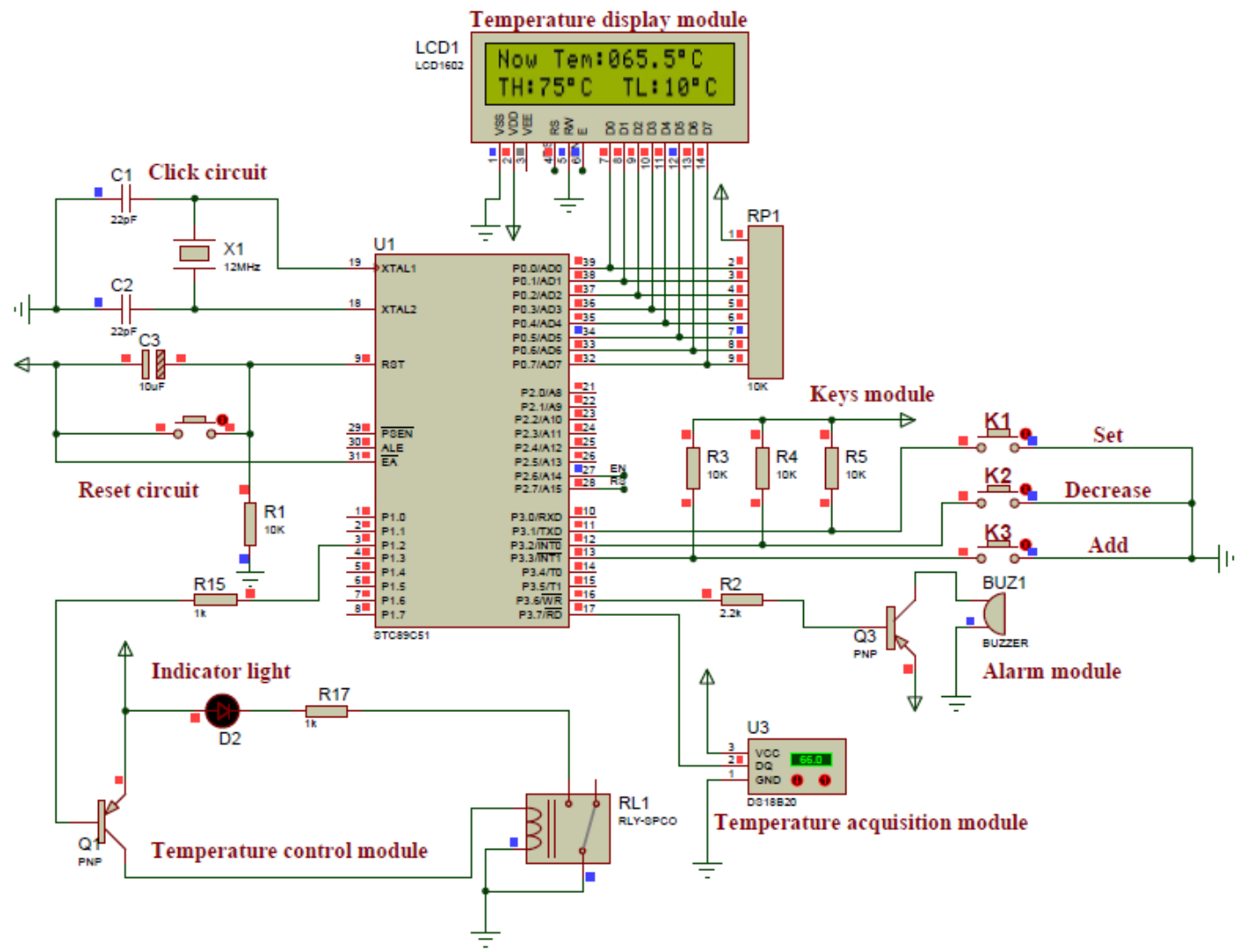

Fig. 7. Simulation of transformer oil temperature setting temperature range 


\section{TEST RESUltS AND ANALYSIS OF CONTROL SySTEM}

In order to verify the feasibility of the control system in Shanghai University of Engineering Science, 1th substation for the actual test, chose a $10 \mathrm{kV}$ oil-immersed transformer, equipped with a cooling fan. Control system can control cooling fan works, control of transformer oil temperature has achieved good results, while achieving fuel temperature monitor and display. Control system to run repeatedly after a period of time, real time measurements of temperature and oil temperature gauge shows the temperature contrasts, as shown in table 1.

TABLE I. THE TRANSFORMER OIL TEMPERATURE MEASUREMENT DATA

\begin{tabular}{|l|l|l|l|l|l|l|l|}
\hline $\begin{array}{l}\text { Display } \\
\text { values } /{ }^{\circ} \mathrm{C}\end{array}$ & 32 & 38 & 42 & 53 & 56 & 60 & 68 \\
\hline $\begin{array}{l}\text { measured } \\
\text { values } /{ }^{\circ} \mathrm{C}\end{array}$ & 32.1 & 38.3 & 41.8 & 53.1 & 56.1 & 59.9 & 68.4 \\
\hline
\end{tabular}

Table 1 shows the transformer oil temperature control system with high accuracy and high stability. In the actual measurement process, due to the presence of magnetic field in the transformer tank, the temperature value part will be a deviation, but the data from multiple measurements can know that the system fully meet the design requirements.

\section{CONCLUSION}

In this design mainly to the transformer oil temperature for detection and control of the object, from hardware and software two parts design, will eventually hardware and software are combined to form the transformer oil temperature intelligent control system, realization of transformer oil temperature detection and control. The real-time temperature detection function provides the accurate data for the analysis of the safe operation of the transformer. Strong alarm and temperature control function, reduce the incidence of safety accidents. The system is a new type of digital transformer temperature detection and control system can be widely used in electric power substation, applicable to the detection and control of many kinds of transformer oil temperature. The intelligent temperature control system can be extended to other fields, and it has a very wide range of applications.

\section{REFERENCES}

[1] Li Pu, Xiang Xuejun, He Tilong. Based on CC1010 transformer oil temperature wireless measurement design [J]. Journal of Three Gorges University Journal (NATURAL SCIENCE EDITION) 2006 (04).

[2] Zhang Qing. Study on the temperature control system of single chip microcomputer [J]. Journal of Shanghai Jiao Tong University, 2007.

[3] Chen Jie, Huang Hong. Sensor and detection technology. Higher Education Press, 2002.

[4] Lai Shouhong. Micro computer control technology [M]. Beijing: Mechanical Industry Press, 2006.

[5] Chen Jing, Zhang Xiaoxi. Design of small constant temperature box based on single chip microcomputer [J].Modern electronic technology, 2014.

[6] LI Chang-Hua, QI Xiang-Dong. Design of Intelligent Control and Monitoring Systems for Power Transformer Oil Temperature[J]. Journal of Taiyuan University of Science \& Technology, 2014.

[7] Lin, Yong Sheng. "Analysis and Countermeasures of a Transformer Oil Temperature Protection Malfunction." Zhejiang Electric Power (2010).

[8] Lesieutre, B. C., W. H. Hagman, and J. L. Kirtley. "An improved transformer top oil temperature model for use in an on-line monitoring and diagnostic system." IEEE Transactions on Power Delivery12.1(1997).

[9] Allan R N, Hizal E M. Prebreakdown phenomena in transformer oil subjected to nonuniform fields $[J]$. Proceedings of the Institution of Electrical Engineers, 1974.

[10] Zhao, Ailing, and J. Huang. "Temperature Control System Based On Single Chip Microcomputer." Journal of Anyang Institute of Technology(2008).

[11] Ou Yajun. The application of Proteus software in the single chip microcomputer experiment $[\mathrm{J}]$. science and technology information, 2006. 